\title{
Correlation between Intrinsic Firing Patterns and Thalamocortical Synaptic Responses of Neurons in Mouse Barrel Cortex
}

\author{
Ariel Agmon ${ }^{1, a}$ and Barry W. Connors ${ }^{2}$ \\ 1Department of Neurology and Neurological Sciences, Stanford University School of Medicine, Stanford, California 94305 \\ and ${ }^{2}$ Section of Neurobiology, Division of Biology and Medicine, Brown University, Providence, Rhode Island 02912
}

\begin{abstract}
We used a thalamocortical slice preparation to record both spike trains and synaptically evoked responses from neurons of mouse barrel cortex. Cells were classified as regular spiking (RS), intrinsically bursting (IB), or fast spiking (FS) according to their temporal firing patterns when injected with current. RS cells were further separated into two subtypes, $\mathbf{R S}_{1}$ and $\mathbf{R S}_{2}$ cells, the latter encountered only in the infragranular layers. Synaptic responses were elicited by focal electrical stimuli in the ventrobasal nucleus of the thalamus (VB) while holding the cells at different membrane potentials. Postsynaptic potentials were classified as excitatory (EPSPs) or inhibitory (IPSPs), and their latencies were measured from the onset of the extracellularly recorded fiber volley in layer IV. EPSPs fell into three groups, according to latency. Those in the early cluster had latencies shorter than $1 \mathrm{msec}$ and were coincident with the postsynaptic layer IV population response; they were considered monosynaptic. A second group, with latencies between 1.3 and $2.5 \mathrm{msec}$, were coincident with all IPSPs and were classified as disynaptic. The rest had latencies longer than $5 \mathrm{msec}$ and were considered polysynaptic. The synaptic order of a cell was correlated with its laminar position and its electrophysiological class. Specifically, monosynaptic responses were restricted to infragranular RS cells and to FS cells, while disynaptic EPSPs were found in supragranular RS cells and in IB cells. Disynaptic IPSPs were found in both deep and superficial layers; in the deep layers they nearly always followed monosynaptic EPSPs, while in the superficial layers they were mostly found in isolation. We conclude that the intrinsic spiking characteristics of a neuron are an important determinant of its position in the cortical circuit and may have a substantial role in determining its response properties.
\end{abstract}

The mammalian neocortex transforms afferent activity induced by sensory stimuli into complex spatiotemporal firing patterns. Classical cortex physiology attempted to characterize this transformation by describing and classifying the variety of response properties encountered in single-unit recordings. Such response

\footnotetext{
Received Apr. 23, 1991; revised July 29, 1991; accepted August 29, 1991.

We thank Dr. Diane O'Dowd for critical reading of the manuscript. A.A. was supported by NIMH Training Grant MH17047. Additional support to B.W.C. came from NIH Grants NS25983 and NS01271 and from the Office of Naval Research.

Correspondence should be addressed to Barry W. Connors, Section of Neurobiology, Box G-M, Division of Biology and Medicine, Brown University, Providence, RI 02912.

${ }^{2}$ Present address: Department of Anatomy and Neurobiology, California College of Medicine, Irvine, CA 92717.

Copyright (C) 1992 Society for Neuroscience $0270-6474 / 92 / 120319-11 \$ 05.00 / 0$
}

properties are determined at two distinct but interrelated levels: the ensemble and the single neuron. The pattern of connections at the ensemble level (the "circuit diagram") determines the inputs to any given cell; however, it is the intrinsic biophysical propertics of the ccll that determine how it will integrate these inputs and what outputs it will generate in response. Various models of neocortical function attempt to explain response properties on the basis of synaptic connectivity; however, the role of intrinsic neuronal properties in the functioning of the neocortical circuit has received surprisingly little experimental or theoretical attention.

One reason for this neglect is the inherent limitation of the extracellular recording technique in revealing membrane properties. A number of single-unit studies have recognized diversity in spike waveforms in the cortex (e.g., Mountcastle et al., 1969; Simons, 1978; Ferrington and Rowe, 1980). However, most single-unit studies (and models based on them) regard neocortex neurons as intrinsically homogeneous, with differences in response properties imposed by their synaptic inputs. A broader appreciation of membrane properties requires intracellular recordings, as was originally demonstrated by in vivo studies (e.g., Takahashi, 1965; Calvin and Sypert, 1976). The advent of the in vitro slice techique has expanded considerably our understanding of cortical membrane physiology. Directly pertinent to the present study is the demonstration in the rodent neocortical slice of three distinct cell classes defined by intrinsic electrophysiological properties (Connors et al., 1982; McCormick et al., 1985). However, the in vitro preparations used so far did not retain the major input pathways to the cortex and thus could only offer limited information about the role of different classes in the cortical circuit. Determining how these classes are incorporated into the functioning network requires a preparation that would allow simultaneous characterization of both a cell's intrinsic physiology and its synaptic connectivity. We have recently described a novel slice preparation of the mouse somatosensory (barrel) cortex and thalamus that meets these requirements (Agmon and Connors, 1991). In the present study, we used this preparation to classify barrel cortex neurons according to their intrinsic firing properties, analyzed in detail their synaptically evoked responses to thalamus stimulation, and looked for a correlation between the circuit-derived properties and the intrinsically originating ones.

\section{Materials and Methods}

Slice preparation and recording techniques. The methods for preparing the mouse thalamocortical slice were described in detail in a previous publication (Agmon and Connors, 1991). In brief, C57 black mice 2-5 weeks of age were anesthetized in halothane and decapitated, and the 




FIELD

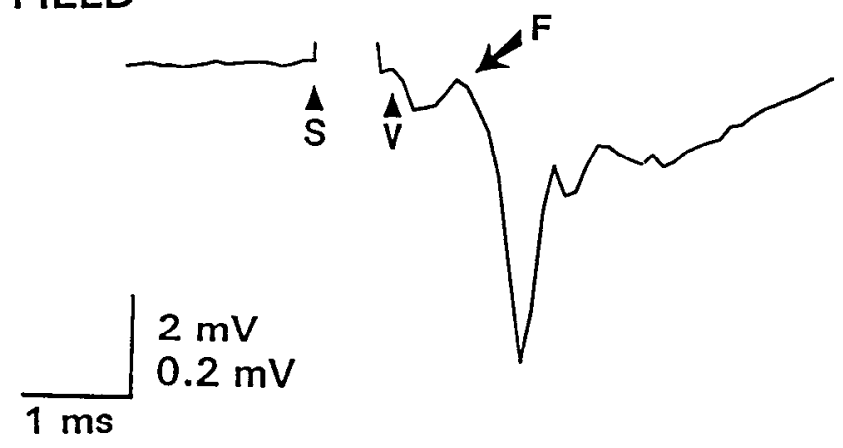

Figure 1. Record from a representative cell illustrating the various events associated with thalamocortical activation. The bottom trace is the extracellularly recorded field potential in layer IV, with onset of stimulus, onset of presynaptic volley, and onset of postsynaptic response marked as $S, V$, and $F$, respectively. The top traces are superimposed intracellularly recorded synaptic responses at hyper- and depolarized membrane potentials. $E$ marks EPSP onset; $I$ marks IPSP onset.

brains were removed into ice-cold artificial cerebrospinal fluid (ACSF). The brains were each positioned at a predetermined angle on a vibratome stage, and $400-\mu \mathrm{m}$-thick slices were cut and collected in order into cold ACSF. Slices were visually screened by transillumination, and those appearing to retain thalamocortical connectivity were placed in an Oslotype interface chamber (Alger et al., 1984). Slices were continuously perfused with ACSF composed of (in $\mathrm{mM}$ ) $\mathrm{NaCl}, 124 ; \mathrm{KCl}, 5 ; \mathrm{NaH}_{2} \mathrm{PO}_{4}$, 1.25; $\mathrm{MgSO}_{d}, 2 ; \mathrm{CaCl}_{2}, 2 ; \mathrm{NaHCO}_{3}, 26 ;$ and dextrose, 10; and saturated with $95 \% \mathrm{O}_{2}$ and $5 \% \mathrm{CO}_{2}$, and allowed at least $1 \mathrm{hr}$ of equilibration while the chamber was gradually warmed up to $32^{\circ} \mathrm{C}$.

A tungsten stimulating microelectrode was placed in the ventrobasal nucleus of the thalamus (VB), and an extracellular recording micropipette filled with isotonic $\mathrm{NaCl}$ was placed in layer IV; their positions were adjusted until a thalamocortical evoked potential with a welldefined fiber volley (Fig. 1) could be elicited. Intracellular recording micropipettes were pulled from thick-wall glass $(1 \mathrm{~mm} \mathrm{o.d.,} 0.5 \mathrm{~mm}$ i.d.) on a Brown-Flaming puller, filled with $4 \mathrm{M}$ potassium acetate, and beveled to a final resistance of 150-200 M 2 . The recording micropipette was advanced through the tissue within a vertical column of about 250 $\mu \mathrm{m}$ to either side of the extracellular microelectrode. When a stable impalement was achieved, the cell's direct responses to intracellularly injected, 350-msec-long square pulses of current (typically from -0.5 to $+1.0 \mathrm{nA}$ ) were recorded, followed by its synaptic responses to 150 $\mu$ sec cathodal stimuli applied to VB. Stimulus levels in VB were adjusted to produce near-maximal extracellular responses in layer IV and were typically $5-10 \mathrm{~V}$. The distance of each cell from the pial surface was measured with an eyepiece micrometer and expressed as a fraction of the pia-white matter distance.

Data acquisition and conditioning. Data were digitized on line at a $10 \mathrm{kHz}$ sampling rate using a microcomputer-based acquisition system. Off-line data conditioning consisted of smoothing, bridge balance correction, and artifact blanking on the current-step responses and of averaging and stimulus artifact subtraction on the synaptically evoked records. Stimulus artifact subtraction was done by fitting the artifact with a single decaying exponential and subtracting it from the data.
Latency measurements. Figure 1 demonstrates, on a representative record, the different events associated with each synaptic response. The bottom trace is the averaged extracellular field potential in layer IV; arrowheads mark the onset of the stimulus artifact (S) and the onset of the presynaptic fiber volley (V). Also marked is the onset of the postsynaptic component of the field potential $(\mathrm{F})$. For a detailed analysis of the thalamocortical field potential, see $\Lambda$ gmon and Connors (1991). The two superimposed traces above are the averaged postsynaptic potentials (PSPs) recorded intracellularly, simultaneously with the field potential. In this cell, both an EPSP and an IPSP were apparent (see below), and their onsets are marked with arrows and labeled $E$ and I, respectively. The five marked events were used to measure four latencies: $\mathrm{S}-\mathrm{V}$, from stimulus onset to fiber volley onset, that is, conduction time in the afferent axons; V-F, from fiber volley onset to onset of postsynaptic population response, a measure of the population-averaged synaptic latency; and finally, V-E and V-I, the latency from fiber volley onset to EPSP and IPSP onset, respectively.

Classification of PSPS. Synaptic responses were usually recorded at resting potential and at two additional membrane potentials maintained by passing constant current through the cell, one hyperpolarized relative to resting and the other depolarized to just below firing threshold. This assured recording on both sides of the IPSP reversal potential, which was usually about $10 \mathrm{mV}$ positive to resting potential (Connors et al., 1988). Absolute membrane potentials were in general uncertain due to the difficulty of achieving bridge balance with the high-impedance microelectrodes used. All synaptic responses were acquired as single sweeps and averaged offline. Several trials (usually eight) were averaged, and the PSP onset (defined as the initial deflection point) was determined from the averaged trace. Responses that were monophasic, positive going at the hyperpolarized potential, and negative going at the depolarized potential, with the same latency (to within $0.2 \mathrm{msec}$ ) at all potentials, were defined as pure IPSPs. Responses that were monophasic, positive going at the hyperpolarized potential, and still positive going or spike eliciting at the depolarized potential were defined as pure EPSPs. Responses that were biphasic (positive-negative), at least at one holding potential, were defined as an EPSP-IPSP sequence. In two cases (see Fig. 5, top left), a response was positive going at the hyperpolarized potential and monophasic negative going at the depolarized potential, but with a later onset (differed by at least $0.4 \mathrm{msec}$ ). Such a response was interpreted as a weak EPSP followed by an IPSP.

\section{Results}

The present report is based on 52 cells from 20 animals. The cells in this sample had an average resting potential of $-72 \mathrm{mV}$ $(\mathrm{SD}=6 \mathrm{mV} ; n=28)$, an average input resistance of $41 \mathrm{M} \Omega$ $(\mathrm{SD}=18 \mathrm{M} \Omega ; n=32$ ), and an average spike height (from rest) of $83 \mathrm{mV}(\mathrm{SD}=10 \mathrm{mV} ; n=39)$.

\section{Firing patterns of barrel cortex cells}

Barrel cortex neurons were divided into four classes, based on their responses to suprathreshold intracellular current steps. Detailed analysis of the electrophysiological properties of these classes will be presented elsewhere; here we shall confine the discussion to the main feature used in defining the four classes, namely, their repetitive firing patterns. It is important to recognize that such patterns are dependent solely on factors intrinsic to the cell, such as its complement of inward and outward ionic currents and possibly its passive cable properties, and are independent of synaptic input (Connors and Gutnick, 1990). These classes were clearly equivalent to those previously described in guinea pig neocortex (Connors et al., 1982; McCormick et al., 1985), and following the same nomenclature, we designated them as regular spiking (RS), fast spiking (FS), and intrinsically bursting (IB). A small subset of the RS cells in the deep layers exhibited a variation on the RS pattern, and we designated this group $\mathrm{RS}_{2}$ (with $\mathrm{RS}_{1}$ being the majority class) following the terminology used by Chagnac-Amitai and Connors (1989) for a similar class of cells in the rat.

Figure 2 illustrates the spiking patterns characteristic to each 


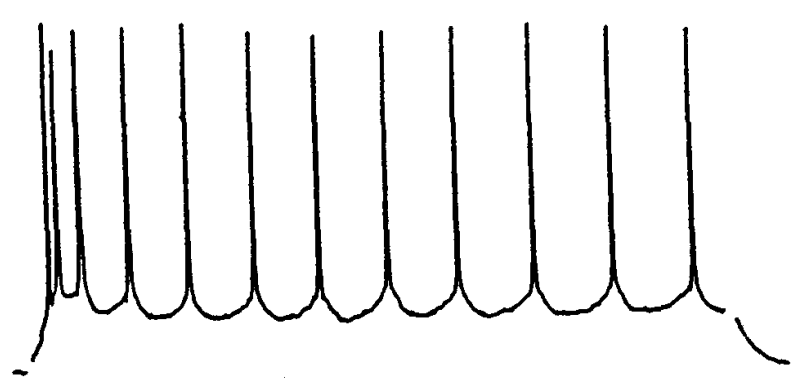

\section{$\mathrm{RS}_{1}$}
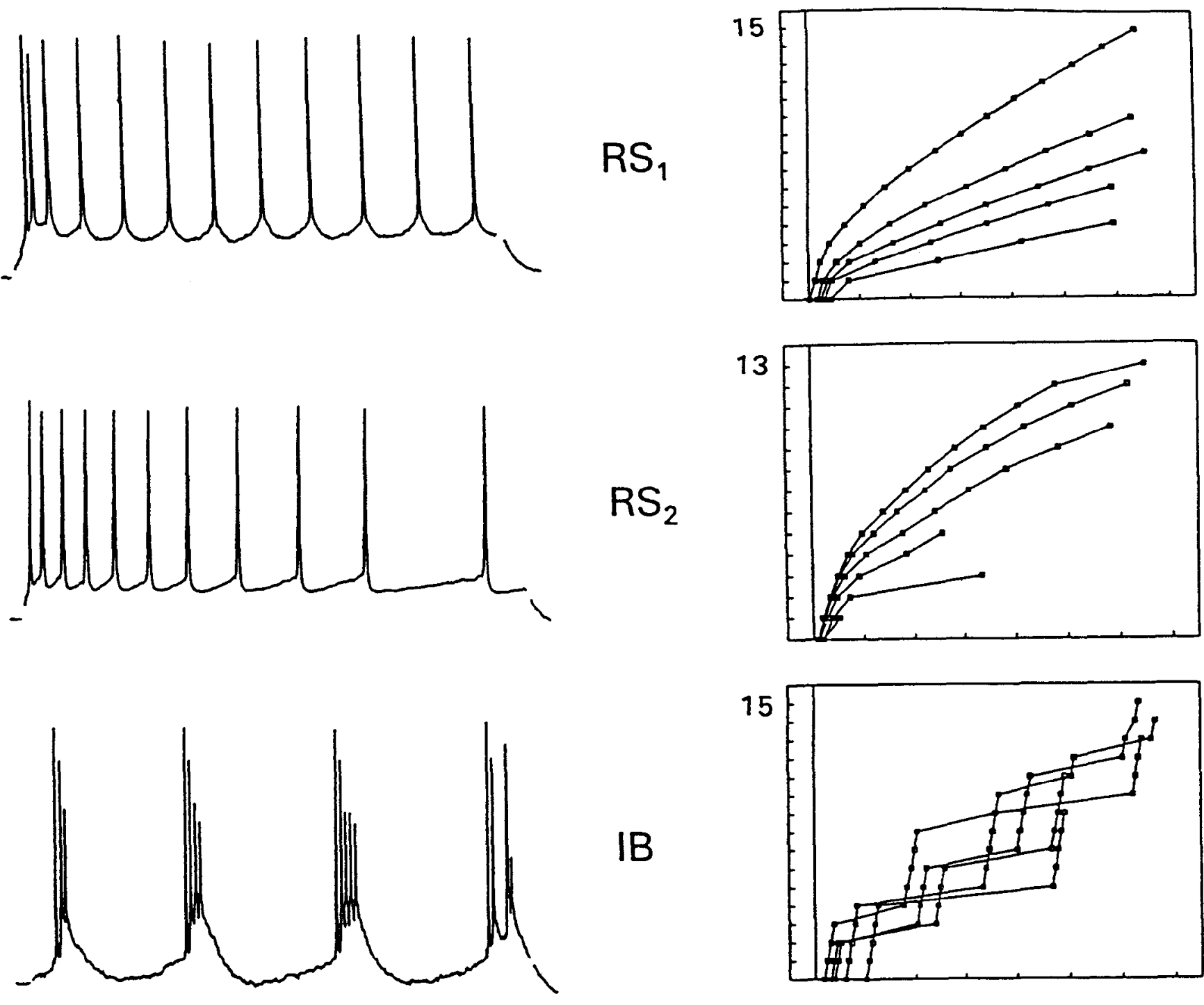

IB
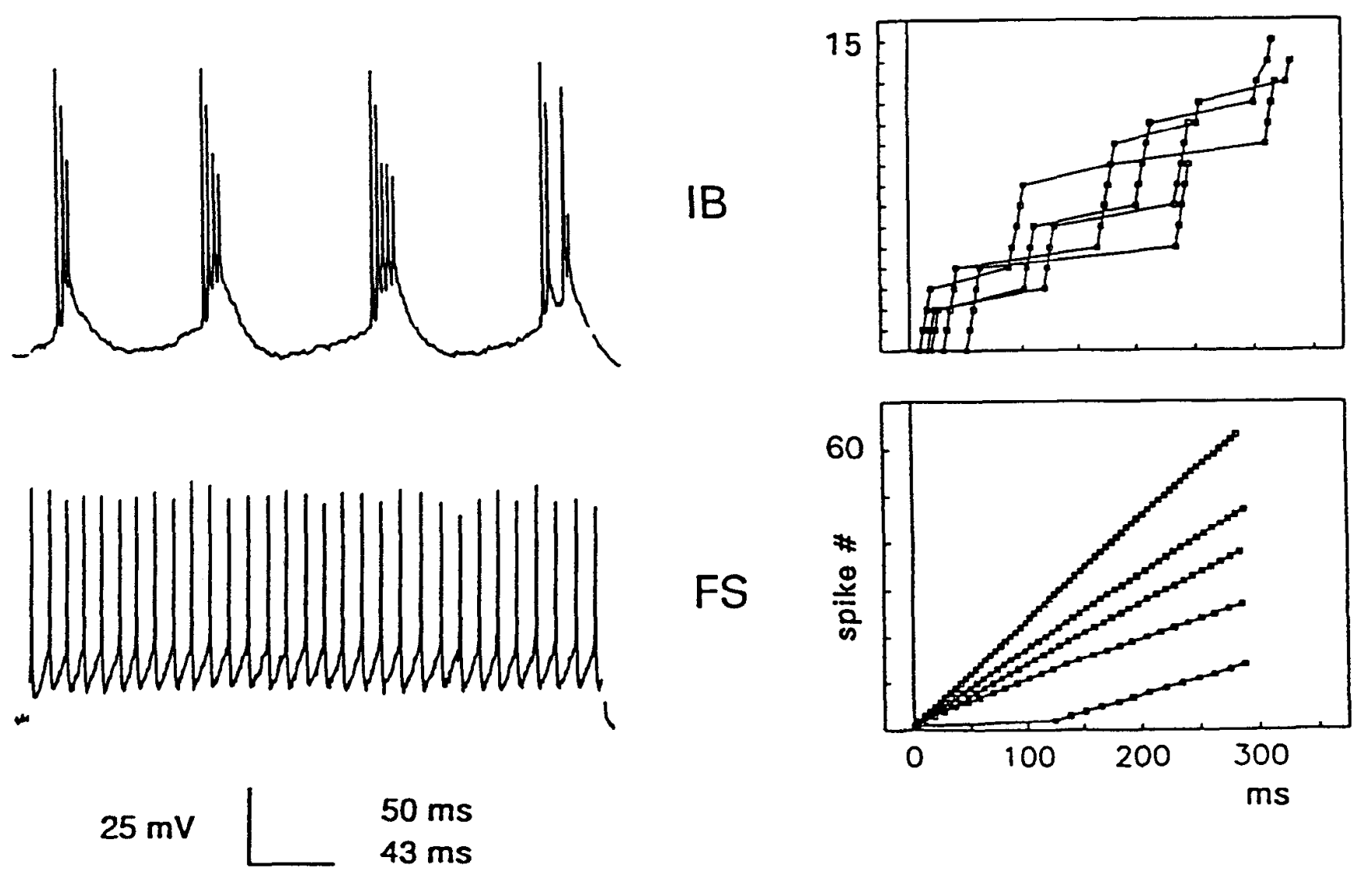

Figure 2. Classification of barrel cortex neurons according to their intrinsic firing patterns. For each class, the left panel is a representative spike Figure 2. Classification of barrel cortex neurons according to their intrinsic firing patterns. For each class, the lamplitudes of the FS cell are an artifact due to digital sampling; diminishing spike amplitudes in each burst of the IB cell are real. The lower time calibration refers to the FS cell. The right panel for each class is a plot of the response of a cell from this class to steps of increasing current intensity. The serial number of each spike is plotted as a function of its time of occurrence after step onset, so the slope of the curves is equal to the instantaneous firing frequency. The differences in firing patterns are evident. Note the different vertical scale for FS cells. 


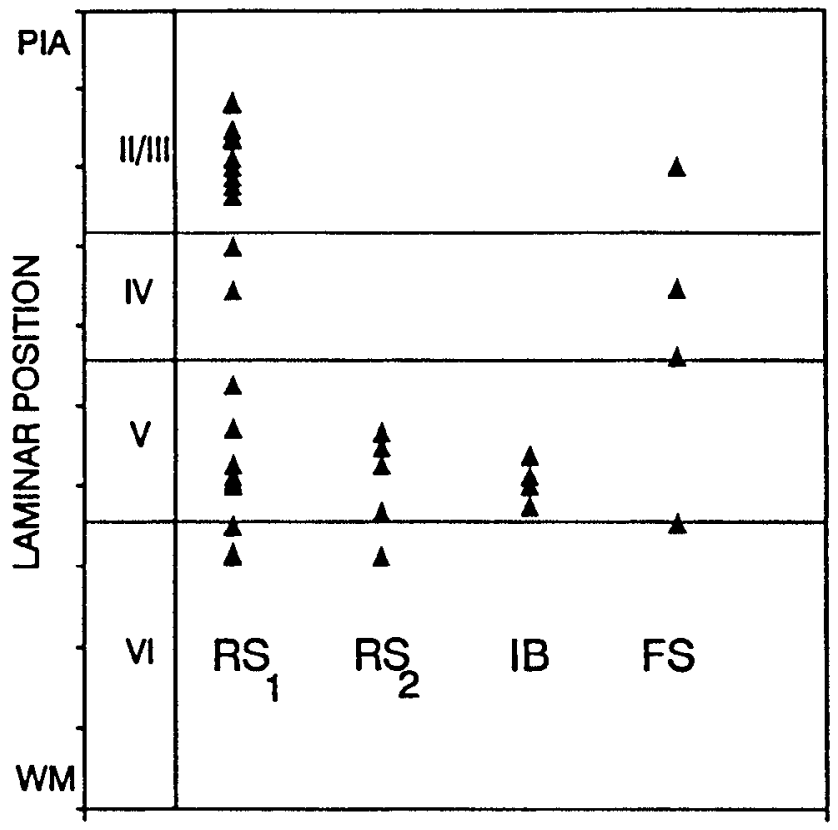

Figure 3. Laminar distribution of cells in our sample. The laminar position of 40 cells is expressed as a fraction of the pia-to-white matter distance and plotted according to electrophysiological class. The cluster of RS cells in layer II/III consists of 16 cells. Twelve cells for which the position data were not recorded are not included. Distances were measured with an eyepiece micrometer during the impalement. Fractional values for the interlaminar borders were averaged from camera lucida drawings of 35 transilluminated slices and are approximate.

class. The left side of the figure shows spike trains recorded from a representative neuron of each class. Each train was elicited by an intracellularly applied current step that lasted between the stimulus artifacts. To the right of each spike train is a graphic representation of several trains elicited in a cell of the same class by increasing current steps. Each spike train is represented by a line plotting the serial number of each spike as a function of its time of occurrence after step onset; the slope of the curve at any time point is thus equal to the instantaneous firing frequency at that point. $\mathrm{RS}_{1}$ cells exhibited a characteristic phase of adaptation during the initial $50-100 \mathrm{msec}$ of the spike train: the firing frequency dropped precipitously during this phase to a rate that stayed relatively constant for the remainder of the current step. In terms of interspike intervals, the first one or two intervals in a train were very short, corresponding to a closely spaced initial doublet or triplet of spikes, while intervals later in the train remained nearly constant. In contrast, in $\mathrm{RS}_{2}$ cells the initial steep reduction in firing frequency was followed by more moderate adaptation that persisted throughout the current step, so subsequent interspike intervals kept increasing until the end of the current injection or until the cell stopped firing altogether. IB cells were characterized by their tendency to fire closely spaced clusters of three or more spikes superimposed on a depolarizing waveform. Most IB cells in the mouse and many IB cells in the rat tend to fire repetitive bursts (Agmon and Connors, 1989; Chagnac-Amitai et al., 1990; Mason and Larkman, 1990; Silva et al., 1991). Finally, FS cells exhibited no adaptation whatsoever and fired evenly spaced action potentials throughout the current pulse. Similar to FS cells in guinea pig neocortex (McCormick et al., 1985), FS cells in our sample had spikes that were of much shorter duration than those of all other cells (A. Agmon and B. W. Connors, unpublished observations) and could attain a much higher maximal firing rate (note the different vertical scale in the bottom right panel of Fig. 2). The aforementioned studies in the guinea pig have suggested that both RS and IB cells are pyramidal in morphology. We filled two infragranular RS cells and one IB cell with the fluorescent dye Lucifer yellow and confirmed this finding for the mouse as well (not shown).

Figure 3 plots the laminar positions of the cells in our sample according to their electrophysiological class. Both $\mathrm{RS}_{1}$ and FS cells were impaled in all cellular layers, while $\mathrm{RS}_{2}$ and IB cells were encountered only in the deep layers (lower $\mathrm{V}$ and upper VI). Based on their laminar position, we subdivided the RS cells into upper RS and lower RS, with the dividing line running approximately in the middle of layer IV. The small number of RS cells successfully impaled in layer IV, probably due to microelectrode bias (see Discussion), precludes their treatment as an independent group. Lower RS cells were of both the $\mathrm{RS}_{1}$ and the $\mathrm{RS}_{2}$ subtypes; however, these two groups were not significantly different in their synaptic responses and consequently will be pooled for the remainder of this report.

\section{Thalamocortical synaptic responses of barrel cortex neurons}

In a majority of the cells, a stimulus applied to VB resulted in a synaptic response. These responses were most probably mediated by the thalamocortical pathway. For reasons elaborated in a previous report (Agmon and Connors, 1991), we believe it is highly unlikely that any of these responses were mediated either by nonspecific pathways or by antidromic activation of corticothalamic neurons. Table 1 lists all the cells in our sample ordered according to their electrophysiological class, together with the latencies of their synaptic responses. The same latencies are plotted as histograms in Figure 4 (see Fig. 1 and Materials and Methods section for the definition of the various latencies measured).

The latencies of most EPSPs (V-E in Table 1, patterned bars in Fig. 4) were shorter than 3 msec. We determined their synaptic order by comparing their latencies with those of two other classes of events, plotted together in Figure 4: layer IV field potentials (solid bars; V-F in Table 1) and IPSPs (open bars; V-I in Table 1). Layer IV is the main thalamocortical termination zone (Herkenham, 1980) and is the site of the earliest (and largest) extracellular current sinks evoked by thalamic stimulation (Mitzdorf and Singer, 1978; Agmon and Connors, 1991). Consequently, postsynaptic field potentials in this layer are good markers for monosynaptic latencies. In addition, since thalamocortical synapses in the barrel cortex are asymmetric and presumably excitatory (White, 1978), any inhibitory response must be at the earliest disynaptic, and IPSPs can thus serve as indicators for disynaptic latencies. Indeed, as Figure $4 \mathrm{dem}$ onstrates, the latencies of layer IV field potentials and IPSPs fall into nonoverlapping time sectors: all layer IV responses occurred earlier than $1.2 \mathrm{msec}$, and all the IPSPs occurred later than $1.5 \mathrm{msec}$. Similarly, the EPSPs were grouped in two nonoverlapping clusters: one with latencies equal to or shorter than $1 \mathrm{msec}$, and the other with latencies equal to or longer than 1.3 $\mathrm{msec}$. On the basis of this separation, we assigned to the early cluster (latencies of $0.3-1.0 \mathrm{msec}$ ) a monosynaptic order and to the late cluster (latencies of 1.3-2.5 msec) a disynaptic order. The remaining EPSPs had long latencies (5-30 msec from the fiber volley) and were often associated with prolonged late events in the field potential that resembled those reported from neo- 
Table 1. Firing patterns and synaptic latencies of all sampled cells

\begin{tabular}{|c|c|c|c|c|c|c|c|c|}
\hline Cell & Age & Layer & Class & P-WM & S-V & $\mathrm{V}-\mathrm{F}$ & V-E & V-I \\
\hline 1 & 27 & $\mathbf{U}$ & $\mathrm{RS}_{\mathrm{1}}$ & 0.17 & - & - & $2.0,5.0$ & - \\
\hline 2 & 25 & $\mathbf{U}$ & $\mathrm{RS}_{1}$ & 0.17 & 0.9 & 1.0 & - & - \\
\hline 3 & 36 & $\mathbf{U}$ & $\mathrm{RS}_{1}$ & 0.24 & 1.0 & 0.9 & 7.6 & 2.4 \\
\hline 4 & 21 & $\mathbf{U}$ & $\mathrm{RS}_{1}$ & 0.24 & 1.3 & 1.0 & 22.0 & 1.8 \\
\hline 5 & 34 & $\mathbf{U}$ & $\mathrm{RS}_{1}$ & 0.16 & 0.9 & 0.7 & - & 2.0 \\
\hline 6 & 19 & $\mathbf{U}$ & $\mathrm{RS}_{1}$ & 0.18 & 1.4 & 0.8 & 13.9 & 2.4 \\
\hline 7 & 20 & $\mathbf{U}$ & $\mathrm{RS}_{1}$ & - & 1.8 & 0.7 & - & 1.6 \\
\hline 8 & 25 & $\mathbf{U}$ & $\mathrm{RS}_{1}$ & - & 0.9 & 0.8 & - & 2.1 \\
\hline 9 & 27 & $\mathbf{U}$ & $\mathrm{RS}_{1}$ & - & 0.8 & 0.9 & 1.4 & - \\
\hline 10 & 27 & $\mathbf{U}$ & $\mathrm{RS}_{1}$ & 0.17 & 1.2 & 0.8 & - & - \\
\hline 11 & 27 & U & $\mathbf{R S}_{1}$ & 0.2 & 1.3 & 0.9 & 8.7 & - \\
\hline 12 & 15 & $\mathrm{U}$ & $\mathbf{R S}_{1}$ & 0.36 & 2.0 & 0.8 & 1.3 & 1.7 \\
\hline 13 & 20 & $\mathrm{U}$ & $\mathbf{R S}_{1}$ & 0.12 & 1.1 & 0.7 & - & 2.6 \\
\hline 14 & 29 & $\mathrm{U}$ & $\mathrm{RS}_{1}$ & 0.21 & 1.5 & 1.0 & 1.5 & - \\
\hline 15 & 25 & $\mathrm{U}$ & $\mathbf{R S}_{1}$ & - & 1.8 & 0.6 & - & - \\
\hline 16 & 27 & $\mathrm{U}$ & $\mathbf{R S}_{1}$ & 0.30 & 1.1 & 0.7 & 5.9 & - \\
\hline 17 & 15 & $\mathrm{U}$ & $\mathrm{RS}_{1}$ & - & - & - & - & - \\
\hline 18 & 27 & $\mathrm{U}$ & $\mathrm{RS}_{\mathrm{l}}$ & 0.15 & 1.0 & 0.9 & 5.4 & - \\
\hline 19 & 24 & $\mathrm{U}$ & $\mathrm{RS}_{1}$ & 0.16 & 0.9 & 1.2 & 5.5 & - \\
\hline 20 & 29 & $\mathrm{U}$ & $\mathrm{RS}_{1}$ & 0.20 & 1.3 & 0.9 & - & - \\
\hline 21 & 24 & $\mathrm{U}$ & $\mathrm{RS}_{1}$ & - & 0.8 & 1.0 & - & - \\
\hline 22 & 17 & $\mathrm{U}$ & $\mathrm{RS}_{1}$ & 0.19 & 1.9 & 0.7 & 2.5 & - \\
\hline 23 & 29 & $\mathrm{U}$ & $\mathrm{RS}_{1}$ & 0.12 & 1.7 & 0.7 & - & - \\
\hline 24 & 27 & $\mathbf{U}$ & $\mathrm{RS}_{1}$ & 0.22 & 2.0 & 0.7 & 5.7 & - \\
\hline 25 & 15 & $\mathbf{U}$ & $\mathrm{RS}_{\mathbf{1}}$ & - & 1.9 & 0.9 & - & - \\
\hline 26 & 25 & $\mathrm{U}$ & $\mathrm{RS}_{\mathbf{1}}$ & - & 1.2 & 0.8 & - & 1.9 \\
\hline 27 & 25 & $\mathrm{~L}$ & $\mathrm{RS}_{1}$ & 0.60 & - & - & - & - \\
\hline 28 & 36 & $\mathbf{L}$ & $\mathrm{RS}_{1}$ & 0.60 & 1.0 & 0.6 & 30.0 & - \\
\hline 29 & 25 & $\mathbf{L}$ & $\mathrm{RS}_{1}$ & 0.59 & 1.2 & 0.6 & 0.7 & 1.9 \\
\hline 30 & 27 & $\mathbf{L}$ & $\mathrm{RS}_{1}$ & 0.48 & 0.9 & 0.6 & - & - \\
\hline 31 & 22 & $\mathbf{L}$ & $\mathrm{RS}_{1}$ & 0.53 & 1.9 & 1.1 & 0.3 & 1.7 \\
\hline 32 & 21 & $\mathbf{L}$ & $\mathrm{RS}_{\mathbf{1}}$ & 0.68 & 1.2 & 0.7 & $0.8,16.0$ & 1.9 \\
\hline 33 & 25 & $\mathbf{L}$ & $\mathrm{RS}_{1}$ & 0.65 & 1.0 & 0.8 & 0.9 & 1.6 \\
\hline 34 & 25 & $\mathbf{L}$ & $\mathrm{RS}_{\mathbf{1}}$ & 0.57 & - & - & - & - \\
\hline 35 & 25 & $\mathbf{L}$ & $\mathrm{RS}_{\mathbf{1}}$ & - & - & - & - & - \\
\hline 36 & 25 & $\mathbf{L}$ & $\mathrm{RS}_{1}$ & 0.69 & 0.9 & 0.6 & 0.9 & 1.8 \\
\hline 37 & 25 & $\mathrm{~L}$ & $\mathrm{RS}_{2}$ & 0.53 & 1.3 & 1.0 & - & 1.8 \\
\hline 38 & 25 & $\mathrm{~L}$ & $\mathrm{RS}_{2}$ & 0.63 & 1.2 & 0.5 & 0.6 & 1.6 \\
\hline 39 & 34 & $\mathbf{L}$ & $\mathrm{RS}_{2}$ & 0.69 & 0.8 & 0.6 & 0.8 & 2.2 \\
\hline 40 & 27 & $\mathbf{L}$ & $\mathrm{RS}_{2}$ & 0.55 & 0.6 & 0.7 & - & - \\
\hline 41 & 25 & $\mathrm{~L}$ & $\mathrm{RS}_{2}$ & 0.57 & - & - & - & - \\
\hline 42 & 25 & - & IB & 0.60 & - & - & - & - \\
\hline 43 & 27 & - & IB & 0.56 & 1.3 & 0.6 & - & - \\
\hline 44 & 21 & - & IB & - & - & - & - & - \\
\hline 45 & 27 & - & IB & 0.56 & 0.9 & 0.6 & 2.4 & - \\
\hline 46 & 22 & - & IB & 0.59 & 1.9 & 1.0 & 1.7 & 2.4 \\
\hline 47 & 27 & - & IB & 0.63 & - & - & - & - \\
\hline 48 & 25 & - & IB & 0.59 & 0.9 & 0.8 & - & 1.9 \\
\hline 49 & 25 & - & FS & 0.20 & 1.9 & 0.8 & 0.8 & - \\
\hline 50 & 21 & - & FS & 0.65 & 1.2 & 0.8 & 0.6 & - \\
\hline 51 & 27 & - & FS & 0.44 & 0.9 & 0.5 & 0.5 & - \\
\hline 52 & 27 & - & FS & 0.35 & 0.8 & 0.6 & 0.7 & - \\
\hline
\end{tabular}

Synaptic latencies for all 52 cells are tabulated according to electrophysiological class. RS cells are designated as upper (U) when the depth from the pial surface, expressed as a fraction of the distance from the pia to the white matter (PWM), is less than 0.4 , and lower (L) otherwise. S-V indicates latency (in msec) from stimulus onset to the onset of the presynaptic fiber volley in layer IV. V-F indicates latency from the fiber volley to the postsynaptic population response in layer IV. V-E and V-I indicate latency from the fiber volley to the EPSP or IPSP onset, respectively. Note that two of the cells ( 1 and 32) received two EPSPs each. Postnatal age of each cell is given in days. 
Figure 4. Synaptic latency histograms of EPSPs (patterned bars), IPSPs (open bars), and layer IV population responses (labeled FIELD; solid bars). Bins are $0.2 \mathrm{msec}$ wide; bin values refer to the upper end of the range (e.g., the bin labeled 0.6 includes all responses that had latencies longer than or equal to 0.4 and shorter than 0.6 ). A total of 29 EPSPs, 19 IPSPs, and 44 population responses are included. The bin on the far right represents all EPSPs with latencies longer than $5 \mathrm{msec}$; no EPSP occurred between 2.4 and $5.0 \mathrm{msec}$. The vertical scale for the field responses is half the scale as marked (i.e., 24 responses per full scale). The EPSP bars are coded according to electrophysiological class (see legend): $U R S$ and $L R S$, upper and lower RS cells, respectively. Note that EPSPs of the FS and lower RS classes are concurrent with the layer IV population responses and considered monosynaptic, while EPSPs of upper RS and IB cells are concurrent with the IPSPs and considered disynaptic.

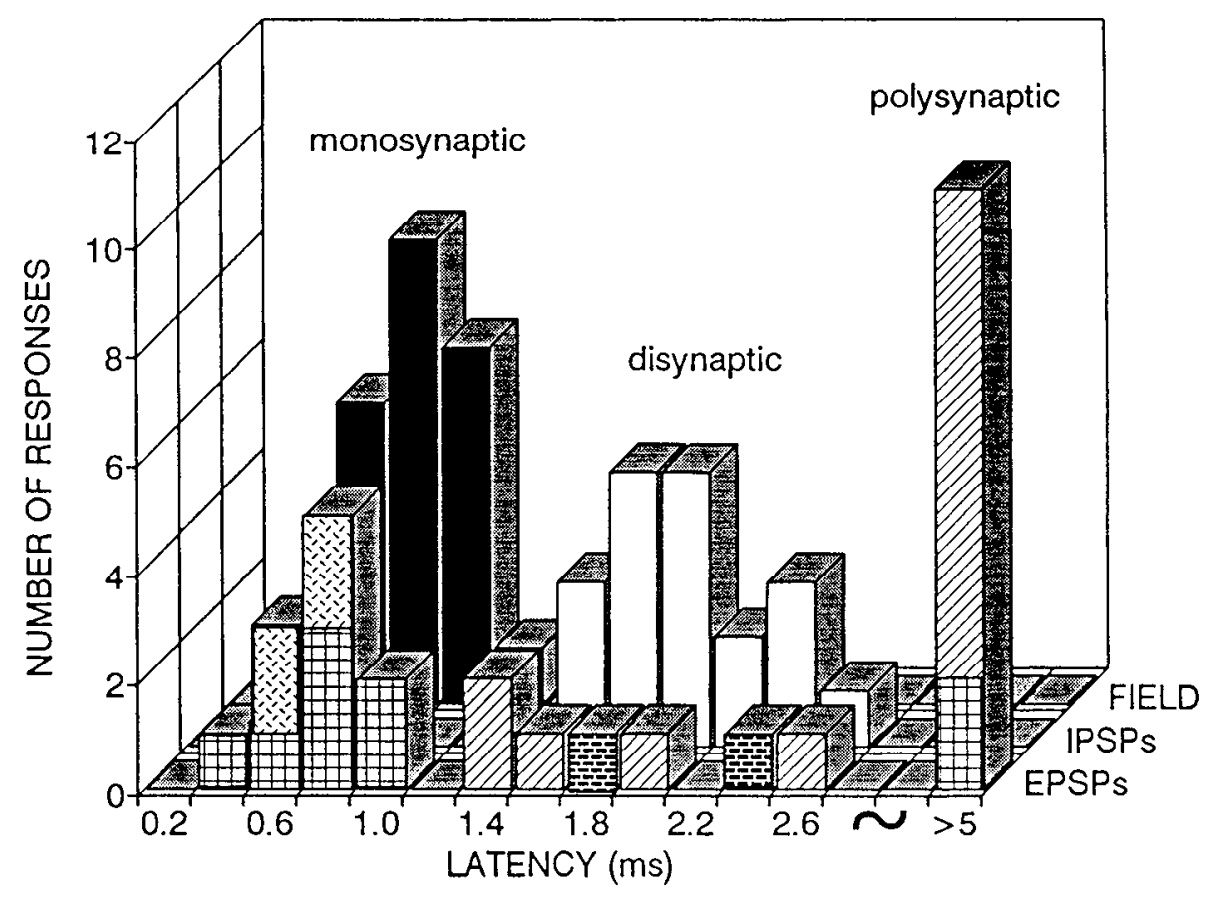

E FS LRS IB URS cortical slices of juvenile rats (Lühmann and Prince, 1990), although in our slices they were found throughout the range of ages used. These late events were considered polysynaptically mediated.

Figure 4 demonstrates a striking correlation between intrinsic firing properties, laminar position, and thalamocortical synaptic input. The EPSPs are plotted in individually patterned bars according to their electrophysiological class (see caption). It is evident from this figure that the monosynaptic cluster was composed exclusively of FS and lower RS cells, while the disynaptic cluster included only upper RS and IB cells.

About one-third of the cells did not exhibit any response above noise level at any membrane potential tested. Such cells were categorized as "unresponsive" and included in our sample only if (1) their recorded response to injected current was indicative of a good impalement and (2) the simultaneously recorded layer IV potential in the same vertical column exhibited a clear thalamocortical response.

Figure 5 shows representative synaptic responses of six cells from the four electrophysiological classes described above. Each cell is represented by two or three traces, the lower at a hyperpolarized membrane potential, the upper slightly below firing threshold, and the middle trace (if present) at or close to resting potential. All traces except those with action potentials are averages of four to eight sweeps. Onsets of EPSPs are marked by a solid arrow; those of IPSPs, by open arrows.

Upper RS cells. About one-quarter of the layer II/III RS cells received a strong disynaptic IPSP with no, or nearly no, EPSP preceding it. At a depolarized membrane potential, just below firing threshold, the IPSP was negative going; at a hyperpolarized membrane potential, the IPSP was reversed (depolarizing). In two cells (one of them illustrated in Fig. 5, top left) this IPSP was preceded by an earlier depolarizing response that was almost indiscernible at a depolarized membrane potential and was never able to fire the cell, even when depolarized to just below threshold. We interpret this component of the response as a disynaptic EPSP that was too close to the ensuing IPSP to have any effect. In three upper RS cells, however, there was a prominent disynaptic EPSP that was not followed by any apparent IPSP. This EPSP always fired the cell from a depolarized membrane potential, and indeed often gave rise to a synaptically induced burst of several spikes (cell at Fig. 5, upper right). Onethird of the upper RS cells received polysynaptic EPSPs, and another quarter did not exhibit any response. The latter were mainly concentrated in the upper half of layer II/III.

Lower RS cells: As mentioned above, we decided to pool infragranular $\mathrm{RS}_{1}$ and $\mathrm{RS}$, cells since there was no significant difference in their synaptic response patterns and latencies. They were, however, markedly different from the upper RS cells. Nearly half of the cells in this category received monosynaptic EPSPs, and the rest were unresponsive. The middle left panel in Figure 5 (from an $\mathrm{RS}_{1}$ cell) and the middle right panel (from an $\mathrm{RS}_{2}$ cell) demonstrate the typical synaptic response in this group. Unlike the supragranular RS cells, all EPSPs in this group were immediately followed by an IPSP, and consequently the cells never fired more than one spike as a result of the EPSP even when held by current injection very close to firing threshold.

$I B$ cells. Two of the seven IB cells in our sample received a weak disynaptic EPSP. One of them is illustrated in Figure 5, bottom left. Two other cells received long-latency EPSPs, and the rest were unresponsive or received only IPSPs.

FS cells. All four FS cells in our sample received a strong EPSP at a monosynaptic latency (1.0 msec or less), which in all but one case caused the cell to fire. An example is shown in Figure 5, bottom right. 


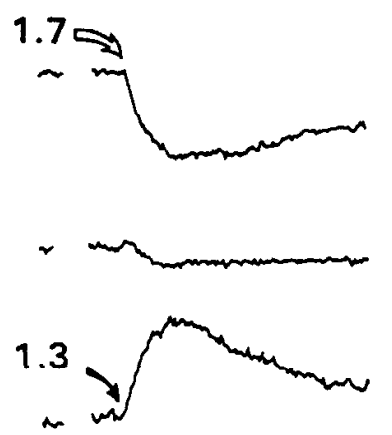

URS


LRS

1.9


IB
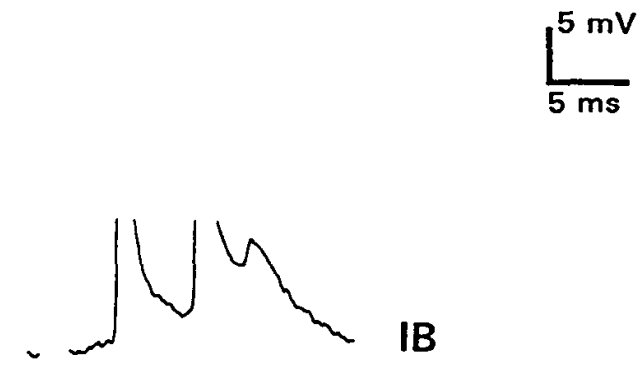

B

FS

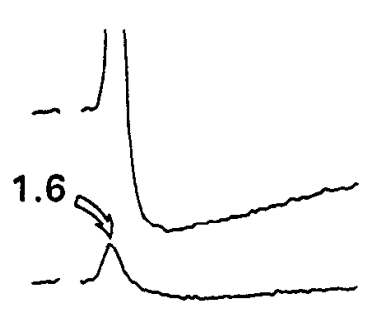

$\int_{0.6}^{1}$

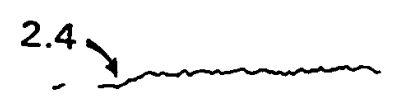

\section{Discussion}

The main finding of the present study is that the intrinsic electrophysiological "fingerprint" of a barrel cortex neuron, in conjunction with its laminar position, is a good predictor of its synaptic order. The electrophysiological classification scheme we have used in this study followed that described in the guinea pig neocortical slice (Connors et al., 1982; McCormick et al., 1985). However, we examined in somewhat more detail the

repetitive firing patterns of the cells and, based on this examination, subdivided the RS group into two subclasses. We then attempted to correlate the classification of the neurons by their intrinsic firing patterns with their classification by synaptic order when activated through the thalamocortical pathway. A correlation was found for the IB and the FS groups: the first never received monosynaptic input, while the second always did. Somewhat more complicated was the finding for the RS groups. Rather than separating according to firing patterns, that is, along 
the $\mathrm{RS}_{1}-\mathrm{RS}_{2}$ division, synaptic latencies were found to correspond with laminar position, such that all responsive upper layers RS cells were disynaptic while all responsive lower layers RS cells, of both subclasses, were monosynaptic.

\section{Determination of synaptic latencies}

Most past studies of thalamocortical synaptic latencies have either measured the latencies from the stimulus, and thus introduced experimental error due to variability in the conduction time between animals, or estimated the arrival time of the fiber volley by extrapolation from the delay between responses to stimulation in two different locations, a procedure that is based on the unproven assumption that the same fibers are stimulated from both sites. In the present study, we circumvented both of these problems by recording the fiber volley directly. This procedure has two potential pitfalls. The first is the tacit assumption of simultaneous arrival time for all the presynaptic action potentials. This can be a problem in systems where there is a large scatter in these velocities, or where a bimodal distribution of velocities has been demonstrated, for example, in the cat geniculocortical pathway (reviewed by Lennie, 1980). Fortunately this is not the case in the rodent. Although there are no direct data on axon diameter distributions in the rodent thalamocortical system, anatomical data indicate a large degree of size homogeneity among the cell bodies in VB (Harris, 1986). In addition, degeneration time in lesioned thalamic afferents in the mouse is markedly uniform (White, 1978). Both of these facts suggest a narrow distribution of axon diameters and consequently of conduction velocities.

There is, however, a second and potentially more serious source of error in this procedure. Infragranular pyramidal cells receive synaptic contacts on their apical dendritic arbor from the thalamocortical axon terminals in layer IV (Peters et al., 1979; White and Hersch, 1982). However, they are also likely to receive synaptic contacts on their basal dendrites from thalamocortical terminals in the layer V/VI tier of terminations (Herkenham, 1980). That they indeed do so is suggested by the early extracellular current sink that can be recorded in that layer (Agmon and Connors, 1991). A more direct proof is a recent result from whole-cell recording experiments in neonatal mice (Agmon et al., 1990). In these studies, many layer V/VI cells were found to receive monosynaptic thalamocortical inputs as early as postnatal day 1 , several days before the development of the barrels and their related thalamocortical axon clusters. These inputs must be arriving through layer V/VI terminals, and unless these synapses are withdrawn later in development, they will continue to convey thalamocortical cxcitation to infragranular cells in the adult animal as well. Since the fiber volley arrives at the layer V/VI border before arriving in layer IV, using the onset of the volley in layer IV as time zero may have caused synaptic latencies of deep cells to be underestimated by (at least) the conduction delay between the two tiers. Based on conduction time from stimulus to fiber volley onset in layer IV ( $\mathrm{S}-\mathrm{V}$ in Table 1) and on distance measurements on living slices, we estimate this delay to be approximately $0.2-0.3 \mathrm{msec}$. Thus, if indeed the lower RS cells in our study received the bulk of their thalamocortical excitation on their basal dendrites, then their real synaptic latencies were actually longer then we report here by that amount. This may explain the inordinately short latency $(0.3 \mathrm{msec})$ of one lower RS cell in our sample. We do not believe that this error, if it indeed occurred, has caused us to misclassify lower RS cells. Even if we shift the bars of lower
RS cells in Figure 4 one or two bins to the right, they would all still have latencies shorter than those of the earliest IPSPs and would justifiably be considered monosynaptic. However, in that case, there would be some overlap with the earliest EPSPs in upper RS cells, and the classification of some of the latter, specifically those earlier than $1.5 \mathrm{msec}$, may have to change from di- to monosynaptic, or at least be considered ambiguous.

\section{Undersampling of layers $I V$ and VI}

Both layer IV and layer VIb were pronouncedly undersampled in our data. Reduced cell density may have contributed to the paucity of impalements in lower layer VI; however, this explanation cannot apply to layer IV, which is the most cell-dense layer of the barrel cortex. Layer IV is composed of small granular cclls, many less than $10 \mu \mathrm{m}$ in diameter (Lorente de Nó, 1922; Pasternak and Woolsey, 1975; Woolsey et al., 1975; Simons and Woolsey, 1984); thus, its undersampling was no doubt the result of microelectrode bias. Such bias does not seem to exist with micropipettes used for whole-cell recordings, and recent studies using this method (Agmon et al., 1990) have confirmed that a great majority of layer IV cells in the barrel cortex receive strong monosynaptic excitation from VB. Single-unit recording latencies are also consistent with monosynaptic excitation of layer IV neurons (Armstrong-James and Fox, 1987).

\section{The meaning of unresponsive cells and the origin of disynaptic PSPS}

Half of the cells in our sample exhibited either pure inhibition or no response at all (Table $1, \mathrm{~V}-\mathrm{E}$ column, $-\mathrm{s}$ ). Lack of response cannot be attributed to impalement-induced damage, sincc only cclls that produced spike records indicative of good impalements were included in the unresponsive group. Neither can it be explained by incomplete retention of thalamocortical fibers in the slice, by fatigue of the thalamocortical synapse, or by stimulus parameters ineffective in activating the afferents, since only when the layer IV field potential showed a clear thalamocortical response were cells classified as unresponsive.

A potential source of error in assessing the fraction and laminar distribution of unresponsive cells could have been the relatively young age of the animals in our sample. Specifically, this could have skewed our data toward an artifactually low fraction of responsive cells in the upper layers, since during early development the upper layers lag behind the deep layers in terms of neurite outgrowth and synaptic connectivity (Miller, 1988). That this was not the case in the present study can be appreciated by perusal of Table 1: 27\% (7 of 26) of our upper RS cells were from animals younger than $21 \mathrm{~d}$, but they accounted for $40 \%$ ( 2 of 5 ) of the disynaptic EPSPs in their class and for $44 \%$ (4 of 9) of the disynaptic IPSPs. Thus, young age in our sample did not bias cells toward low connectivity.

We suspect that unresponsive or purely inhibited neurons are cells in which potential polysynaptic inputs were not realized because a precursor cell did not fire. When hippocampal slices are bathed in low levels of GABA antagonist, polysynaptic responses are uncovered in cells that did not exhibit them before (Miles and Wong, 1987). The need to disinhibit the cortex for such latent polysynaptic inputs to be expressed may be an artifact of the slice preparation, since resting potentials in the slice tend to be more negative than in vivo (Connors et al., 1982), causing many cells that receive EPSPs not to reach firing threshold and consequently not to excite any of their follower cells. Indeed, in our sample, cells that received excitation were usually 
fired by the EPSP only when depolarized to near firing threshold. Only two groups of cells in our sample seemed to fire readily even from rest: FS cells and (according to the extracellular evidence) layer IV cells. Consequently, all disynaptic responses in our sample can probably be traced back to an action potential in one of these two groups. FS cells are considered inhibitory and thus probably account for at least some of the disynaptic IPSPs that we found to be so ubiquitous. Layer IV contains both inhibitory (smooth or sparsely spiny) and excitatory (spiny) interneurons (Lorente de Nó, 1922; Woolsey et al., 1975). The latter have been shown anatomically to project to the upper layers (Lund, 1987) and may well be the source for the disynaptic EPSPs that we found in some of the upper RS cells. Since they seem to have been the only excitatory population that was regularly fired by thalamic stimulation, they may have also been the source of disynaptic EPSPs in two IB cells.

\section{Comparison with previous studies}

A large body of previous work deals with thalamocortical synaptic circuitry and falls into two main categories: electron microscopic examination of labeled synapses, and in vivo electrophysiological recordings of extracellular or, rarely, intracellular responses to electrical stimulation of the thalamus. Indirect inferences about circuitry can also be made from in vivo recordings of responses to physiological stimulation, and recent latency studies in whisker harrel cortex of mouse and rat essentially agree with the results presented here (Armstrong-James and Fox, 1990; Welker et al., 1990). Of particular interest is a comparison of our results with the findings of White and co-workers, who over the last decade have conducted a painstaking morphological, ultrastructural, and immunocytochemical study of the thalamocortical connectivity of the mouse barrel cortex (reviewed in White, 1989). As detailed below, our results are in substantial agreement with these previous works, and this agreement extends to all the cell classes that we studied, supporting our belief that the in vitro preparation that we used retained all the major elements of the thalamocortical circuit.

Deep RS cells. Corticothalamic cells are located around the layer V/VI border (White and Keller, 1987) and have apical dendrites that seldom branch above layer IV (Katz, 1987), a morphological distinction that is shared by many infragranular RS cells (Chagnac-Amitai et al., 1990). Thus, at least some of our lower RS cells may have been corticothalamic projection neurons. White and Hersch (1981) report that corticothalamic pyramidal cells receive a large fraction $(12-20 \%)$ of their presynaptic contacts in layer IV from thalamocortical afferents, and indeed, in our sample, RS cells in the layers V/VI border had a high likelihood of receiving monosynaptic thalamic input.

FS cells. Both immunocytochemically defined GABA cells and morphologically defined nonspiny cells have been repeatedly shown to receive thalamocortical synapses (e.g., White, 1978; Peters et al., 1979; Hornung and Garey, 1981; Freund et al., 1985), albeit to varying degrees (White and Rock, 1981). In vitro studies have correlated at least one subset of these cells with a distinct electrophysiological class, the FS cells (McCormick ct al., 1985; Hucttner and Baughman, 1988; Naegele and Katz, 1990). The present study closes the circle by demonstrating that FS cells are indeed strongly excited by the thalamocortical afferents at a monosynaptic latency. In a study of physiologically evoked responses of rat barrel cortex, Simons (1978) reports recording infrequently from "fast-spiking units" in layer IV that had much shorter spike waveforms than the majority of cells and that followed more faithfully patterns of afferent inputs. It is very likely that these units correspond to FS cells, which in our study also tended to be highly responsive to thalamic input.

Superficial RS cells. White and Hersch (1981) report that in layer IV dendritic segments of layer III pyramidal cells receive only $2.5-6.5 \%$ of their presynaptic boutons from thalamocortical afferents. This must be considered an upper limit on the fraction of thalamocortical boutons over the whole cell, since many dendritic segments of these cells may not cross into layer IV at all. Consequently, one would predict that the direct physiological effect of thalamocortical activity on these cells would be small to negligible. Indeed, we found no monosynaptic EPSPs in these cells, with the aforementioned caveat that some of the earliest EPSPs in this group may have been monosynaptic. This finding is in partial disagreement with some previous in vivo studies of cat visual cortex (Toyama et al., 1974; Ferster and Lindstrom, 1983; Martin and Whitteridge, 1984), which reported both disynaptic and monosynaptic responses in layer II/ III, with the latter being more prevalent in the lower part of this layer; however, it is consistent with the report by Bullier and Henry (1979).

$I B$ cells. We found that IB cells in layer V did not receive direct thalamocortical input. In an intracellular in vivo study in the cat visual cortex, Ferster and Lindstrom (1983) describe a specific subset of layer $\mathrm{V}$ cells that is similarly never monosynaptic-the corticotectal projection neurons. Recent combined anatomical and electrophysiological studies (Chagnac-Amitai et al., 1990; Larkman and Mason, 1990) have shown that IB cells have distinct morphology. Specifically, they have thick apical dendrites that ascend all the way to layer I and branch repeatedly in the upper layers. A similar description holds for rodent corticotectal or corticopontine cells (Hallman et al., 1988; Hubener and Bolz, 1988), suggesting that at least some of the IB cells are indeed corticotectal/corticopontine. These populations have not yet been studied by White and his co-workers, but based on the above correlations, we would predict that they would be found to receive only a negligible percentage of thalamocortical boutons. In this context, it deserves mentioning that Lorente de Nó, in a classic Golgi study of the barrel cortex (1922), describes a category of layer $\mathrm{V}$ cells with thick apical dendrites passing all the way to layer I and comments that they give out very few spines in layer IV and thus may not be affected physiologically by the afferents.

\section{The synaptic organization of intracortical inhibition}

About one-third of the cells in our sample received a disynaptic IPSP. Since thalamocortical synapses are asymmetric and thus excitatory (but see Einstein et al., 1987, for a rare dissenting report), such IPSPs must be mediated by intracortical inhibitory interneurons that receive monosynaptic inputs in parallel with the cells that are inhibited by them. White and Keller (1987) describe exactly such a triadic arrangement by which both corticothalamic cells and GABAergic interneurons are postsynaptic to thalamocortical boutons, and the corticothalamic cells receive contacts from the same GAB $\Lambda$ ergic interneurons. From the above discussion, it is evident that the electrophysiological equivalent of this anatomical triad would be FS cells receiving monosynaptic excitation and deep RS cells receiving monosynaptic excitation followed by disynaptic inhibition, which is exactly what we report in the present study. Such a triadic arrangement may serve as a temporal barrier on the excitation, preventing the 
Figure 6. A circuit diagram of the barrel cortex, depicting the synaptic relationships between the four cell classes and the thalamocortical afferents $(V B)$. Fxcitatory synapses are represented as short lines; inhibitory terminals, as dots. Except for the monosynaptic inputs onto the spiny stellate cell (in layer IV) and its putative identification as the source of disynaptic input to the upper layers, all the synaptic connections in the diagram have been directly observed in the present study with intracellular recordings.

cells from firing more than one spike as a result of the monosynaptic EPSP. However, in the superficial layers, we found a different relationship between excitation and inhibition: monosynaptic excitation was scarce, some cells received only disynaptic IPSPs apparently without excitation, while others received disynaptic EPSPs with apparently no inhibition. Thus, inhibition in the superficial layers acted more as a spatial barrier, allowing some cells to be driven by disynaptic EPSPs, while rendering the rest unsusceptible to excitation.

\section{The synaptic circuitry of the barrel cortex}

Figure 6 is an attempt to put our data into the framework of a neuronal circuit. The thalamic afferents are seen to contact three representative cells: an FS cell in layer IV, an RS cell in lower layer V, and a spiny stellate cell (depicted as an RS cell) in layer IV. The FS cell is assumed to be an inhibitory interneuron, and it conveys a disynaptic IPSP to the deep RS cell, as well as to an upper RS cell, while the spiny stellate cell conveys a disynaptic EPSP to another upper RS cell. Finally, an IB cell is depicted as receiving a polysynaptic EPSP from an unspecified source. With the exception of the input onto the spiny stellate cell, all of these connections have been observed intracellularly in the present study. This putative circuit diagram shares many features with a variety of previous attempts to describe the connectivity pattern of the cortical network (e.g., review by Jones, 1984). Its main novelty is in the way it defines the circuit elements themselves. Previous definitions were based upon laminar position, morphology, biochemistry, receptive field properties, and/or axonal targets. The present study strongly suggests that an important component of the definition should be intrinsic electrophysiological characteristics.
It seems indisputable that the intrinsic firing properties of a cortical neuron will play a major role in determining its behavior during integration of synaptic inputs derived from physiological stimuli. However, the precise interaction between extrinsic inputs and intrinsic properties cannot be directly deduced from our data. It is intriguing to note, however, that cells in the input layer (in the neuronal network sense) of the cortex, that is, cells that are the direct recipients of the thalamocortical input, are strongly adapting when excitatory (RS cells) and strongly nonadapting when inhibitory (FS cells), properties that will no doubt attenuate the overall firing rate in the network. On the other hand, cells that occupy a higher position in the cortical circuit, the IB cells, have firing properties that can accentuate or amplify whatever input they may receive. One tendency of this distribution of firing properties would be to equalize the average firing rate between the different layers of the network. Why this should be so is as yet unclear, as is much else regarding the interaction between synaptic connectivity and intrinsic properties in the functioning of the primary sensory cortex. The thalamocortical slice promises to be a productive vehicle for studying such fundamental issues.

\section{References}

Agmon A, Connors BW (1989) Repetitive burst-firing neurons in the deep layers of mouse somatosensory cortex. Neurosci Lett 99:137141

Agmon A, Connors BW (1991) Thalamocortical responses of mouse somatosensory (barrel) cortex in vitro. Neuroscience 41:365-380.

Agmon A, O'Dowd DK, Jones EG (1990) Development of thalamocortical responses in barrel cortex of early postnatal mice. Soc Neurosci Abstr 16:631.

Alger BE, Dhanjal SS, Dingledine R, Garthwaite J, Henderson G, King GL, Lipton P, North A, Schwartzkroin PA, Sears TA, Segal M, Whit- 
tingham TS, Williams J (1984) Brain slice methods. In: Brain slices (Dingledine R, ed), pp 381-437. New York: Plenum.

Armstrong-James M, Fox K (1987) Spatiotemporal convergence and divergence in rat S1 "barrel" cortex. J Comp Neurol 263:265-281.

Armstrong-James M, Fox K (1990) Intracolumnar and interlaminar relay of vibrissal information in barrelfield cortex. Soc Neurosci Abstr $16: 1215$.

Bullier J, Henry GH (1979) Ordinal position of neurons in cat striate cortex. J Neurophysiol 42:1251-1263.

Calvin WH, Sypert GW (1976) Fast and slow pyramidal tract neurons: an intracellular analysis of their contrasting repetitive firing properties in the cat. J Neurophysiol 39:420-434.

Chagnac-Amitai Y, Connors BW (1989) Synchronized excitation and inhibition driven by intrinsically bursting neurons in neocortex. $J$ Neurophysiol 62:1149-1162.

Chagnac-Amitai Y, Lühmann HJ, Prince DA (1990) Burst generating and regular spiking layer 5 pyramidal neurons of rat neocortex have different morphological features. J Comp Neurol 296:598-613.

Connors BW, Gutnick MJ (1990) Intrinsic firing patterns of diverse neocortical neurons. Trends Neurosci 13:99-104.

Connors BW, Gutnick MJ, Prince DA (1982) Electrophysiological properties of neocortical neurons in vitro. J Neurophysiol 48:13021320.

Connors BW, Malenka RC, Silva LR (1988) Two inhibitory postsynaptic potentials, and $\mathrm{GABA}_{\mathrm{A}}$ and $\mathrm{GABA}_{\mathrm{B}}$ receptor-mediated responses in neocortex of rat and cat. J Physiol (Lond) 406:443-468.

Einstein G, Davis TL, Sterling P (1987) Ultrastructure of synapses from the A-laminae of the lateral geniculate nucleus in layer IV of the cat striate cortex. J Comp Neurol 260:63-75.

Ferrington DG, Rowe M (1980) Differential contributions to coding of cutaneous vibratory information by cortical somatosensory areas I and II. J Neurophysiol 43:310-331.

Ferster D, Lindstrom S (1983) An intracellular analysis of geniculocortical connectivity in area 17 of the cat. J Physiol (Lond) 342:181215.

Freund TF, Martin KA, Somogyi P, Whitteridge D (1985) Innervation of cat visual areas 17 and 18 by physiologically identified $X$ - and Y-type thalamic afferents. II. Identification of postsynaptic targets by GABA immunocytochemistry and Golgi impregnation. J Comp Neurol 242:275-291.

Hallman LE, Schofield BR, Lin CS (1988) Dendritic morphology and axon collaterals of corticotectal corticopontine and callosal neurons in layer $\mathrm{V}$ of primary visual cortex of the hooded rat. J Comp Neurol 272:149-160.

Harris RM (1986) Morphology of physiologically identified thalamocortical relay neurons in the rat ventrobasal thalamus. J Comp Neurol 251:491-505.

Herkenham M (1980) Laminar organization of thalamic projections to the rat neocortex. Science 207:532-534.

Hornung JP, Garey LJ (1981) The thalamic projection to cat visual cortex: ultrastructure of neurons identified by Golgi impregnation or retrograde horseradish peroxidase transport. Neuroscience 6:10531068 .

Hubener M, Bolz J (1988) Morphology of identified projection neurons in layer 5 of rat visual cortex. Neurosci Lett 94:76-81.

Huettner JE, Baughman RW (1988) The pharmacology of synapses formed by identified corticocollicular neurons in primary cultures of rat visual cortex. J Neurosci 8:160-175.

Jones EG (1984) Identification and classification of intrinsic circuit elements in the neocortex. In: Dynamic aspects of neocortical function (Edelman GM, Gall WE, Cowan WM, eds), pp 7-40. New York: Wiley.

Katz LC (1987) Local circuitry of identified projection neurons in cat visual cortex brain slices. J Neurosci 7:1223-1249.

Larkman A, Mason A (1990) Correlations between morphology and electrophysiology of pyramidal neurons in slices of rat visual cortex. I. Establishment of cell classes. J Neurosci 10:1407-1414.

Lennie P (1980) Parallel visual pathways: a review. Vision Res 20: 561-594.

Lorente de Nó R (1922) La corteza cerebral del raton. Trab Inst Cajal Invest Biol 20:41-78.

Lühmann HJ, Prince DA (1990) Control of NMDA receptor-mediated activity by GABAergic mechanisms in mature and developing rat neocortex. Neurosci Lett 111:109-115.

Lund JS (1987) Local circuit neurons of macaque monkey striate cortex: I. Neurons of laminae $4 \mathrm{C}$ and 5A. J Comp Neurol 257:6092.

Martin KA, Whitteridge D (1984) Form function and intracortical projections of spiny neurones in the striate visual cortex of the cat. J Physiol (Lond) 353:463-504.

Mason A, Larkman A (1990) Correlations between morphology and electrophysiology of pyramidal neurons in slices of rat visual cortex. II. Electrophysiology. J Neurosci 10:1415-1428.

McCormick DA, Connors BW, Lighthall JW, Prince DA (1985) Comparative electrophysiology of pyramidal and sparsely spiny stellate neurons of the neocortex. J Neurophysiol 54:782-806.

Miles R, Wong RK (1987) Inhibitory control of local excitatory circuits in the guinea-pig hippocampus. J Physiol (Lond) 388:611-629.

Miller MW (1988) Development of projection and local circuit neurons in neocortex. In: Cerebral cortex, Vol 7, Development and maturation of cerebral cortex (Peters A, Jones EG, eds), pp 133-175. New York: Plenum.

Mitzdorf U, Singer W (1978) Prominent excitatory pathways in the cat visual cortex (A 17 and A 18): a current source density analysis of electrically evoked potentials. Exp Brain Res 33:371-394.

Mountcastle VB, Talbot WH, Sakata H, Hyvärinen J (1969) Cortical neuronal mechanisms in flutter-vibration studied in unanesthetized monkeys. Neuronal periodicily and frequency discrimination. J Neurophysiol 32:452-484.

Naegele JR, Katz LC (1990) Cell surface molecules containing $\mathrm{N}$-acetylgalactosamine are associated with basket cells and neurogliaform cells in cat visual cortex. J Neurosci 10:540-557.

Pasternak JR, Woolsey TA (1975) The number of size and spatial distribution of neurons in lamina IV of the mouse SmI neocortex. J Comp Neurol 160:291-306.

Peters A, Proskauer CC, Feldman ML, Kimerer L (1979) The projection of the lateral geniculate nucleus to area 17 of the rat cerebral cortex. V. Degenerating axon terminals synapsing with Golgi impregnated neurons. J Neurocytol 8:331-357.

Silva LR, Amitai Y, Connors BW (1991) Intrinsic oscillations of neocortex generated by layer 5 pyramidal neurons. Science 251:432-435.

Simons DJ (1978) Response properties of vibrissa units in rat SI somatosensory neocortex. J Neurophysiol 41:798-820.

Simons DJ, Woolsey TA (1984) Morphology of Golgi-Cox-impregnated barrel neurons in rat SmI cortex. J Comp Neurol 230:119-132.

Takahashi K (1965) Slow and fast groups of pyramidal tract cells and their respective membrane properties. J Neurophysiol 28:908-924.

Toyama K, Matsunami K, Ono T, Tokashiki S (1974) An intracellular study of neuronal organization in the visual cortex. Exp Brain Res 21:45-66.

Welker E, Armstrong-James M, Van der Loos H (1990) Physiological aspects of the barrel cortex of the mouse: a single unit laminar latency analysis. Soc Neurosci Abstr 16:1215.

White EL (1978) Identified neurons in mouse SmI cortex that are postsynaptic to thalamocortical axon terminals: a combined Golgielectron microscopic and degeneration study. J Comp Neurol 181: $627-662$.

White EL (1989) Cortical circuits. Boston: Birkhäuser.

White EL, Hersch SM (1981) Thalamocortical synapses of pyramidal cells which project from SmI to MsI cortex in the mouse. J Comp Neurol 198:167-181.

White EL, Hersch SM (1982) A quantitative study of thalamocortical and other synapses involving the apical dendrites of corticothalamic projection cells in mouse SmI cortex. J Neurocytol 11:137-157.

White EL, Keller A (1987) Intrinsic circuitry involving the local axon collaterals of corticothalamic projection cells in mouse SmI cortex. J Comp Neurol 262:13-26.

White EL, Rock MP (1981) A comparison of thalamocortical and other synaptic inputs to dendrites of two non-spiny neurons in a single barrel of mouse SmI cortex. J Comp Neurol 195:265-277.

Woolsey TA, Dierker ML, Wann DF (1975) Mouse SmI cortex: qualitative and quantitative classification of Golgi-impregnated barrel neurons. Proc Natl Acad Sci USA 72:2165-2169. 